\title{
Fully human VEGFR2 monoclonal antibody BC001 attenuates tumor angiogenesis and inhibits tumor growth
}

\author{
ZI-XUE XUAN ${ }^{1,3}$, LIN-NA LI ${ }^{1}$, QI ZHANG ${ }^{1}$, CHENG-WANG XU $^{1}$, DE-XUAN YANG ${ }^{1}$, YE YUAN $^{2}$, \\ YING-HONG AN ${ }^{1}$, SHAN-SHAN WANG ${ }^{1}$, XIAO-WEN LI $^{2}$ and SHOU-JUN YUAN ${ }^{1}$ \\ ${ }^{1}$ Department of Pharmacology and Toxicology, Beijing Institute of Radiation Medicine, Beijing 100850; \\ ${ }^{2}$ Department of Production Technology, Shandong Buchang Shenzhou Pharmaceutical Co., Ltd., Heze 274000; \\ ${ }^{3}$ Department of Pharmacy, Zhejiang Provincial People's Hospital, Hangzhou 310014, P.R. China
}

Received August 5, 2014; Accepted September 19, 2014

DOI: $10.3892 / \mathrm{ijo} .2014 .2690$

\begin{abstract}
The critical role of VEGFR2 in tumor neovascularization and progression has allowed the design of clinically beneficial therapies based on it. Here we show that BC001, a new fully human anti-VEGFR2 monoclonal antibody, inhibits VEGF-stimulated endothelial cell migration, tube formation, and effectively suppressed the transdifferentiation of cancer stem cells into endothelial cells in vitro. Since BC001 exhibited no activity against the mouse VEGFR2 and mouse based study was required to confirm its efficacy

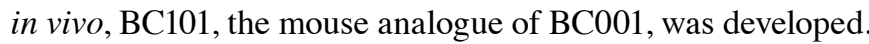
BC101 significantly attenuated angiogenesis according to Matrigel plug assay and resulted in $\sim 80 \%$ growth inhibition of mouse B16F10 homograft tumors relative to vehicle control. Similarly, human analogue BC001 suppressed the growth of human xenograft tumors HCT116 and BGC823. Furthermore, immunohistochemical results showed reduced expression of CD31, VEGFR2 and Ki-67, as well as increased expression of Caspase 3 in BC001-treated tumor, which indicated BC001 was able to significantly decrease microvessel density, suppress proliferation and promote apoptosis. These results demonstrate the fully human VEGFR2 monoclonal antibody BC001 can work as an effective inhibitor of tumor angiogenesis and tumor growth both in vitro and in vivo.
\end{abstract}

\section{Introduction}

Tumor angiogenesis is characterized by the formation of new irregular blood vessels from pre-existing vascular network, transdifferentiation and vasculogenic mimicry of cancer

Correspondence to: Professor Shou-Jun Yuan, Department of Pharmacology and Toxicology, Beijing Institute of Radiation Medicine, Beijing 100850, P.R. China

E-mail: yuansj@nic.bmi.ac.cn

E-mail: yuansj_bmi@163.com

Key words: VEGFR2, endothelial cells, tumor angiogenesis, transdifferentiation, tumor growth stem cells, and it is generally accepted to be a rate-limiting process during tumor growth $(1,2)$, so antiangiogenic drugs have become a crucial strategy of therapy in multiple tumors (3-5). Vascular endothelial growth factors (VEGFs) are important regulators of vascular development during angiogenesis, which have five ligands (VEGF-A, -B, -C, -D and PLGF) and exert their biological activities by binding to three receptor tyrosine kinases (RTKs), known as VEGF receptor-1, -2 and -3 (VEGFR1-3), as well as to co-receptors (6). In certain respects, the important role of VEGF-VEGFR signaling pathway during development and in neovascularization of tumor has allowed the design of clinically beneficial therapies, after the first molecular-targeted antiangiogenic therapy with Bevacizumab was approved by the FDA and was used as first-line therapy in colorectal cancer (CRC) (7). Several clinical successes indeed occured in accordance with our expectation, but questions also emerged in clinic, especially about the limited efficacy, the side effects, and the resistance to antiangiogenic therapy (8). In order to design more successful therapies, these questions must be addressed even though they represented potential challenges.

With a general interest in dissecting VEGFR2 signaling, a growing number of evidence demonstrates that VEGFR2 is predominantly responsible for responses of vascular endothelial cells to VEGF under both physiological and pathological conditions, and plays important role in the process of angiogenesis through affecting vascular permeability, proliferation, survival and migration $(9,10)$. However, as a therapeutic target, the attractiveness of VEGFR2 is multifaceted. For instance, VEGFR2 is not only highly expressed on the surface of tumorrelated endothelial cells, but also expressed directly on tumor cells (11). So selective VEGFR2 blockades can lead to inhibition of receptor phosphorylation and tumor angiogenesis, as well as tumor cell apoptosis, ultimately leading to tumor regression (12). Importantly, selective inhibition of VEGFR2, can be tailored to attenuate only specific signal-transduction pathways and do not affect any other RTKs, so they should eliminate toxicity reactions resulting from off-target receptor inhibitions, which is a frequent phenomenon observed by nonspecific inhibitors of VEGF receptors.

BC001 is a new fully human monoclonal antibody against VEGFR2. In this study, we evaluated the effect of BC001 on 
tumor growth and tumor angiogenesis. Additionally, cancer stem cells can also develop a vascular phenotype, to promote tumor angiogenesis through direct transdifferentiation into endothelial cells (13-15). Furthermore, activation of the VEGFR2 in glioma stem cells (GSCs) is an important mediator for this process $(16,17)$, suggesting that successful blockage of VEGFR2 activity might negatively impact the transdifferentiation of GSCs. Therefore, our study would demonstrate the inhibitory effect of BC001 on GSCs transdifferentiation.

\section{Materials and methods}

Cell culture. Human umbilical vein endothelial cell (HUVEC) was obtained from ScienCell Research Laboratories. HUVECs were cultured in conditioned endothelial cell medium (ECM), containing basal ECM (ScienCell Research Laboratories, USA), 5\% fetal bovine serum (FBS, cat. no. 0025), 1\% endothelial cell growth supplement (ECGS, cat. no. 1052), $1 \%$ penicillin/streptomycin solution (P/S, cat. no. 0503$)$ at $37^{\circ} \mathrm{C}$ under an atmosphere of $5 \% \mathrm{CO}_{2} / 95 \%$ air. The mouse melanoma cell line $\mathrm{B} 16 \mathrm{~F} 10$, the human colorectal cancer cell line HCT116 and human gastric cancer cell line BGC823 were purchased from Cell Resource Center (PUMC, China) and cultured in RPMI-1640 supplemented with 10\% FBS.

HUVEC migration assay. HUVECs were allowed to grow into full confluence in 96-well plates pre-coated with PLL $(2 \mu \mathrm{g} /$ $\mathrm{cm}^{2}$ ) and then incubated with basal ECM medium for $2 \mathrm{~h}$ to inactivate HUVEC proliferation. Then, cells were wounded by pipette tips and washed with PBS. Basal ECM medium supplemented with different concentrations of BC001 were added into the wells with or without $25 \mathrm{ng} / \mathrm{ml}$ VEGF. Images were taken after $\sim 16 \mathrm{~h}$ of incubation at $37^{\circ} \mathrm{C}, 5 \% \mathrm{CO}_{2}$, and the gaps of migrated cells were quantified by Image software.

Transwell migration assay. HUVECs were seeded into 24-well 8.0- $\mu \mathrm{m}$-pore inserts of Transwell chamber (Millipore) at $2 \times 10^{5}$ cells $/ \mathrm{ml}$. These Transwell inserts containing HUVECs were placed into a 24 -well plate (Costar) containing basal ECM medium supplemented with $2 \%$ serum and different concentrations of BC001. When HUVECs were incubated for $2 \mathrm{~h}$ at $37^{\circ} \mathrm{C}$, VEGF (20 ng/ml) were added into the lower well of the chamber to stimulate HUVECs migration. After $12 \mathrm{~h}$, the cells on the upper surface of the membrane (non-migrated cells) were scraped with a cotton swab and the cells spreading on the lower sides of the membrane (migrated cells) were fixed with cold $4 \%$ paraformaldehyde for $30 \mathrm{~min}$, and were stained with crystal violet for $15 \mathrm{~min}$. Images were taken and migrated cells were quantified by manual counting.

HUVEC tubule formation assay. The spontaneous formation of capillary-like structures by HUVECs on Matrigel (Becton-Dickinson, Bedford, MA, USA), is widely used to assess the efficiency of antiangiogenic drugs $(18,19)$. 96-well plates (Costar) were coated with Matrigel $(10 \mathrm{mg} / \mathrm{ml})$ according to the manufacturer's instructions. HUVECs $\left(2 \times 10^{5}\right.$ cells $\left./ \mathrm{ml}\right)$ were seeded on Matrigel-coated plates and incubated in basal ECM medium in the presence or absence of BC001, and the cultures were incubated at $37^{\circ} \mathrm{C}$ for $24 \mathrm{~h}$. Capillary-like structures were observed and three randomly selected microscopic
Table I. The gene sequences of primers.

\begin{tabular}{ll}
\hline Primer & \multicolumn{1}{c}{ Gene sequence } \\
\hline \multirow{2}{*}{ Actin } & 5'-TTC CTT CCT GGG CAT GGA GTC CTG-3' \\
& 5'-GAG GAG CAA TGA TCT TGA TCT TCA-3' \\
CD133 & 5'-AGG CAC TTA CGG CAC TCT TC-3' \\
& 5'-TTT CTT CCT GCT GCA CCC AA-3' \\
Nestin & 5'-CTG GAG CAG GAG AAA CAG GG-3' \\
& 5'-CTG AGG GAA GTC TTG GAG CC-3' \\
VEGFR2 & 5'-CCA GGC AAC GTA AGT GTT CGA G-3' \\
& 5'-GGG ACC CAC GTC CTA AAC AAA G-3' \\
CD31 & 5'-CCA GTG TCC CCA GAA GCA AA-3' \\
& 5'-TGA TAA CCA CTG CAA TAA GTC CTT TC-3' \\
CD34 & 5'-ACG GCC ATT CAG CAA GAC AAC-3' \\
& 5'-GCA CGT GGT CAG ATG CAG AGA-3' \\
vWF & 5'-AGC CCA TTT GCT GAG CCT TG-3' \\
& 5'-CCT GGC ACC ATG CAT TTC TG-3' \\
\hline
\end{tabular}

fields were photographed after $24 \mathrm{~h}$. Thereafter, these tubular structure formations were quantified by calculating the tube length using Image software.

The effect of BC001 on transdifferentiation of stem-like U87. To establish the stem-like U87, U87 cells were cultured as previously reported, with serum-free DMEM/F12K (Gibco) plus EGF $10 \mathrm{ng} / \mathrm{ml}$, bFGF $15 \mathrm{ng} / \mathrm{ml}$, 2\% B27 supplement, and $1 \%$ penicillin/streptomycin, and in 6-well plates with ultra low attachment surface (Corning Life Sciences). Nestin is a glioma stem cells marker, we identified stem-like U87 cells through detecting the expression of CD133 and Nestin (16). After the single cells had grown to single-cell spheres, and these cells were identified through evaluating the ratio of $\mathrm{CD} 133^{+}$cells by FACS (Becton-Dickinson), total RNA of stem-like U87 was extracted, and we analysed the expression of CD133, Nestin and VEGFR2 using real-time PCR. According to a previous method (20), we established the transdifferentiation model of stem-like U87 to ECs in vitro and carried out real-time PCR to investigate the endothelial markers CD31, CD34, and vWF. The tubular networks of stem-like U87 with or without BC001 (5 and $20 \mu \mathrm{g} / \mathrm{ml}$ ) were imaged, and the influence of BC001 on expression of CD31, CD34, and vWF was analyzed. The primers used are listed in Table I.

Animal studies. According to the experimental design, female C57 mice and athymic nude mice were needed. The animals were maintained in a laminar air flow cabinet under aseptic conditions. The care and treatment of experimental animals were in accordance with the guideline established by the National Science Council of China, and our experiment was conducted following the guideline of the State Food and Drug Administration.

Matrigel plug assay. Matrigel plug assay was performed as described by Pang et al and Adini et al (21,22). In brief, 

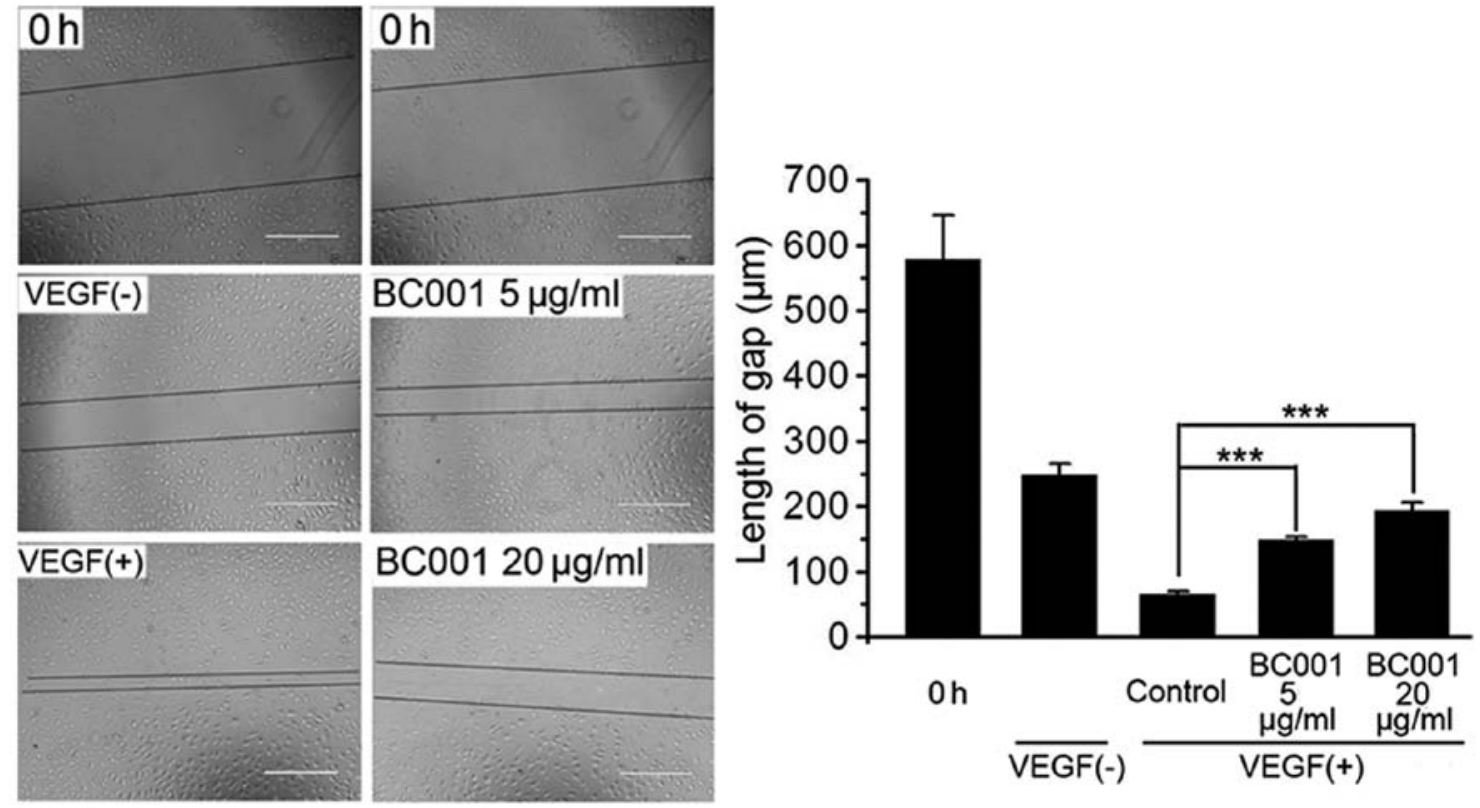

Figure 1. BC001 inhibits endothelial cells migration. After incubation with BC001, the migrated cells were decreased, compared to that of VEGF(+) group, this result showed BC001 inhibited HUVEC migration. Scale bar, $400 \mu \mathrm{m}$.

Matrigel $(0.5 \mathrm{ml} / \mathrm{plug})$ with VEGF $(4 \mathrm{ng} / \mathrm{ml})$ and heparin $(20 \mathrm{U})$ was injected s.c. in the abdominal region of 5- to 6 -week-old C57 mice (n=3 each group). The next day, 20 and $40 \mathrm{mg} / \mathrm{kg} \mathrm{BC101}$ was administered i.v. twice a week. After 3 administrations, the mice were sacrificed and the plugs were removed. After photography, the Matrigel plugs were fixed and embedded with paraffin, then stained with H\&E, angiogenesis was also characterized by CD31 immunostaining.

Tumor growth in vivo. Mouse B16F10 cells $\left(1 \times 10^{6}\right.$ cells $\left./ \mathrm{ml}\right)$ were subcutaneously inoculated in the right axillary fossa of 50 C57 female mice. Mice were randomly divided into 5 groups $(\mathrm{n}=10)$, and the treatments with the $4 \mathrm{mg} / \mathrm{kg}$ bevacizumab or 10,20 and $40 \mathrm{mg} / \mathrm{kg} \mathrm{BC} 101$ were initiated the next day after tumor cell inoculation. All the treatments were administered i.v. twice a week for a total of 6 times.

Human HCT116 cells $\left(1 \times 10^{6}\right.$ cells $\left./ \mathrm{ml}\right)$ were injected s.c. into 5 nude mice. When tumor volume was about $400 \mathrm{~mm}^{3}$, tumors were chopped into fragments, then we transplanted them subcutaneously into nude mice (23). Treatment with $4 \mathrm{mg} / \mathrm{kg}$ bevacizumab or 5,10 and $20 \mathrm{mg} / \mathrm{kg} \mathrm{BC} 001$, given as described above, was initiated 1 day after transplantation and continued for 4 weeks. Furthermore, human BGC823 xenograft assay was performed according to the above method. Tumor size was measured in two perpendicular dimensions with calipers, then tumor volume was calculated using the formula: $\left(a b^{2}\right) / 2$, where $a$ was the length and $b$ was the width of tumor, respectively. After administration, mice were sacrificed and the tumors were harvested, measured and photographed, finally fixed in $4 \%$ formalin.

Histology and immunohistochemistry. Formalin-fixed, paraffin-embedded HCT116 tumor tissues of control group, bevacizumab $(4 \mathrm{mg} / \mathrm{kg})$ group and BC001 $(10 \mathrm{mg} / \mathrm{kg})$ group were examined, as follows. The tissue sections were stained with $\mathrm{H} \& \mathrm{E}$, and immunohistochemistry staining with the primary antibody against Ki-67 (Dako, 1:100 dilution), Caspase 3 (Abcam, 1:100 dilution), hCD31 (Dako, 1:50 dilution), and VEGFR2 (Bioworld, 1:50 dilution), the following method were as previously described. To quantify Ki-67 immunostaining, the positive nucleus was calculated in five random microscopic areas, Caspase 3 immunostaining showed apoptotic cells. To quantify the number of intratumoral vessels, the number of CD31 positive areas was calculated. Additionally, we illuminated the changes of VEGFR2 expression using VEGFR2 immunostaining. Images were taken with Zeiss Axioskop 40 photomicroscope.

Statistical analysis. The data are presented as mean $\pm \mathrm{SD}$, and statistical comparisons between groups were carried out using one-way analysis of variance or Student's t-test. P-values $<0.05$ were considered statistically significant. ${ }^{*} \mathrm{P}<0.05,{ }^{* *} \mathrm{P}<0.01$, ${ }^{* * * *} \mathrm{P}<0.001$ (in figures).

\section{Results}

BC001 impairs the migration of HUVECs. Endothelial cell migration and invasion are of importance for forming blood vessels in angiogenesis and thus are necessary for tumor growth and metastasis. VEGFR2 is crucial factor mediating the migratory and invasive abilities of endothelial cell, so we next investigated the effects of $\mathrm{BC} 001$ on the chemotactic motility of HUVECs using wound-healing and Transwell migration assays. As shown in Fig. 1, compared to VEGFinduced group, the length of gaps with BC001 treatment (5 and $20 \mu \mathrm{g} / \mathrm{ml}$ ) decreased significantly. Similarly, VEGF-induced migration of HUVECs was reduced by BC001 (5 and $20 \mu \mathrm{g} /$ ml) treatment (Fig. 2A). Taken together, BC001 effectively inhibited VEGF-induced migration of HUVECs.

BC001 abates tube formation of endothelial cells. Although the process of tumor angiogenesis is very complicated, tube 

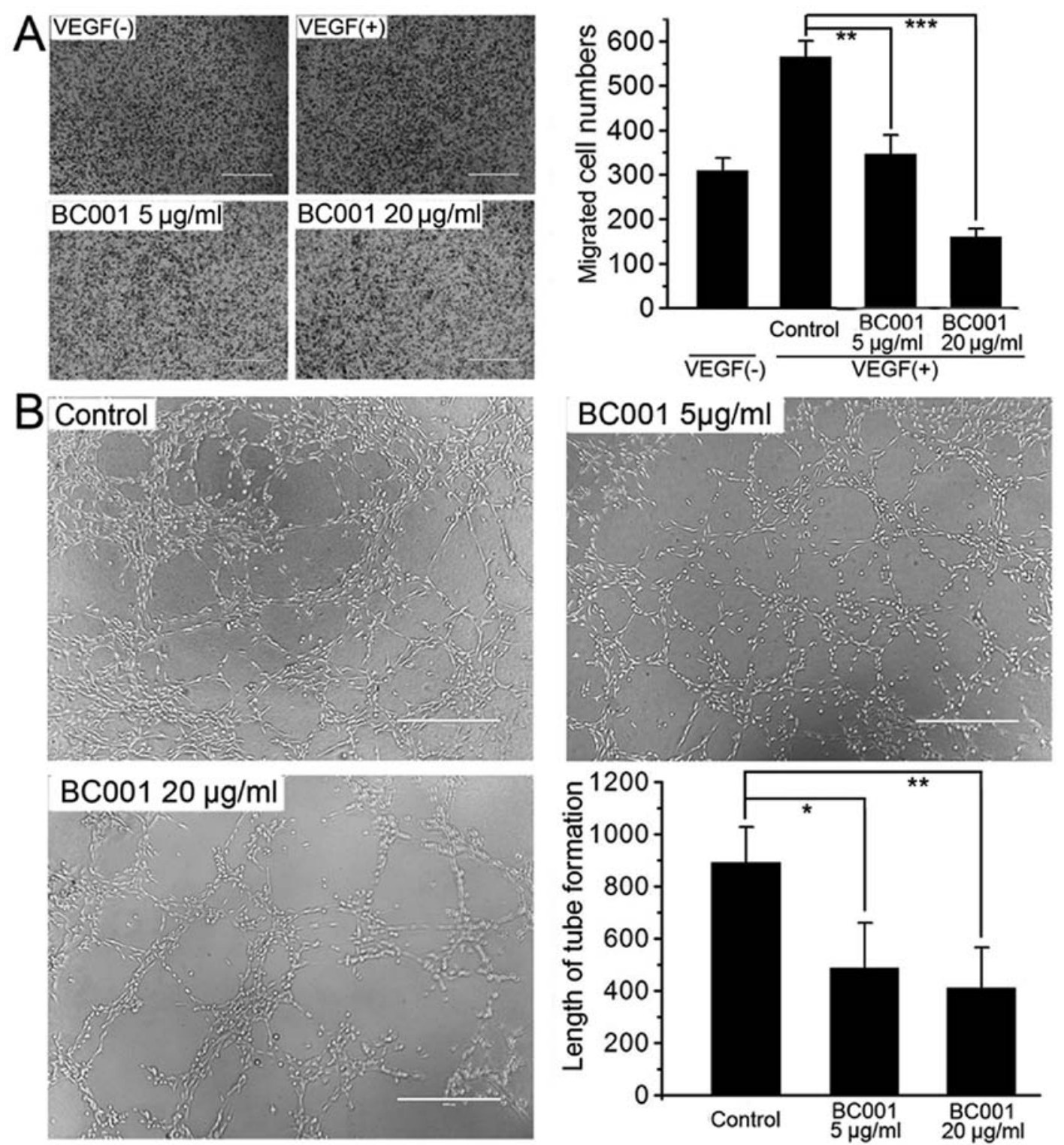

Figure 2. BC001 inhibits VEGF-induced Transwell migration, and tubular structure formation of endothelial cells. (A) The inhibitory effect of BC001 on HUVEC Transwell migration. HUVECs were seeded into Transwell inserts and treated with BC001, and the bottom chamber was filled with conditioned ECM medium supplemented with VEGF, then migrated cells were counted. Scale bar, $400 \mu \mathrm{m}$. (B) BC001 inhibited VEGF-induced tube formation of HUVECs. HUVECs were placed in the 96-well plates coated with Matrigel. After treatment of BC001, cells were fixed and tubular structure was quantified. Scale bar, $400 \mu \mathrm{m}$.

formation of endothelial cells is one of the key steps. To examine the potential role of BC001 in angiogenesis, we investigated the effect of the drug on vascular endothelial tube formation in vitro. We measured the cumulative the length of capillary-like structure and found that BC001 (5 and $20 \mu \mathrm{g} / \mathrm{ml})$ significantly impaired the tube formation compared to the control group (Fig. 2B).

BC001 inhibits the transdifferentiation of stem-like U87. It is generally accepted that tube-formation assay is not limited to test vascular behavior for ECs, tumor cells or tumor stem cells can also develop a vascular phenotype, through direct transdifferentiation into ECs (24-26). VEGFR2 is activated in glioma stem cells, and mediates the process of transdifferentiation, thus, successful blockage of VEGFR2 activity might inhibit the transdifferentiation of glioma stem cells (27-29).
To obtain stem-like cells from U87 cell line, U87 cells were cultured with serum-free DMEM/F12 medium containing EGF, bFGF, B27 supplement in ultra low attachment surface 6 -well plates. Fifteen days later, big tumorspheres formed with diameter of $\sim 200 \mu \mathrm{m}$ (Fig. 3A). Then the stem-like U87 spheres were digested with Accutase solution and harvested. FACS analysis showed an obvious increase of the CD133+ cells in U87 tumorspheres (Fig. 3B). qRT-PCR assay further revealed the upregulation of glioma stem cell markers CD133, Nestin and VEGFR2 in U87 cells obtained from tumorspheres (Fig. 3C). These results confirmed the stem cell-like phenotypes of U87 cells derived from tumorspheres. The stem-like U87 cells were then used to establish the transdifferentiation model into ECs on Matrigel (Fig. 3D) and significantly increased expression of CD31, CD34 and vWF in the transdifferentiated cells indicated the effectiveness and reliability of 

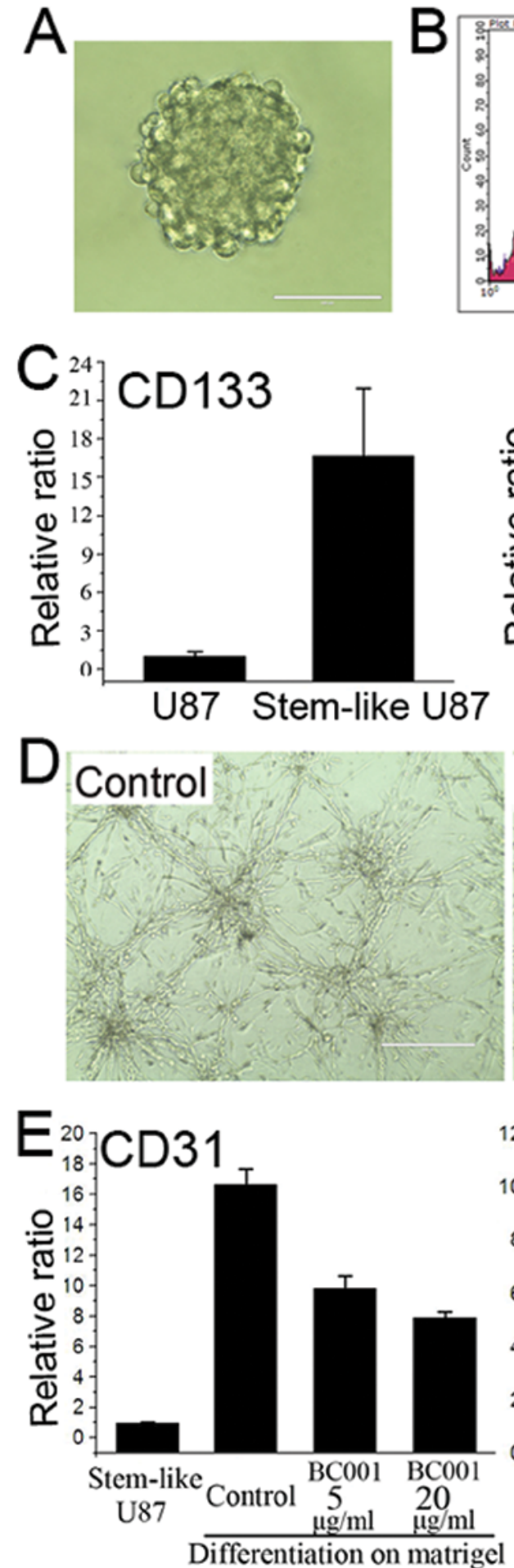
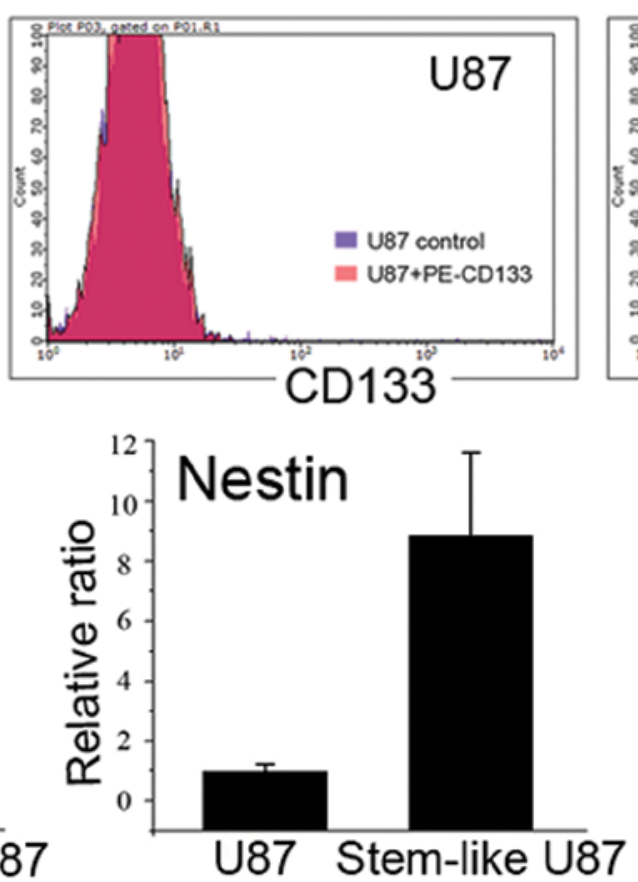
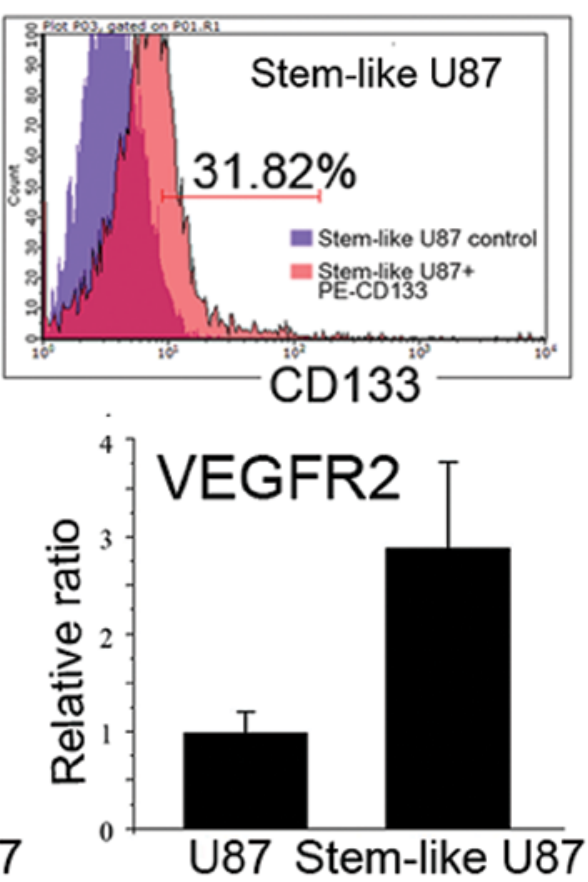
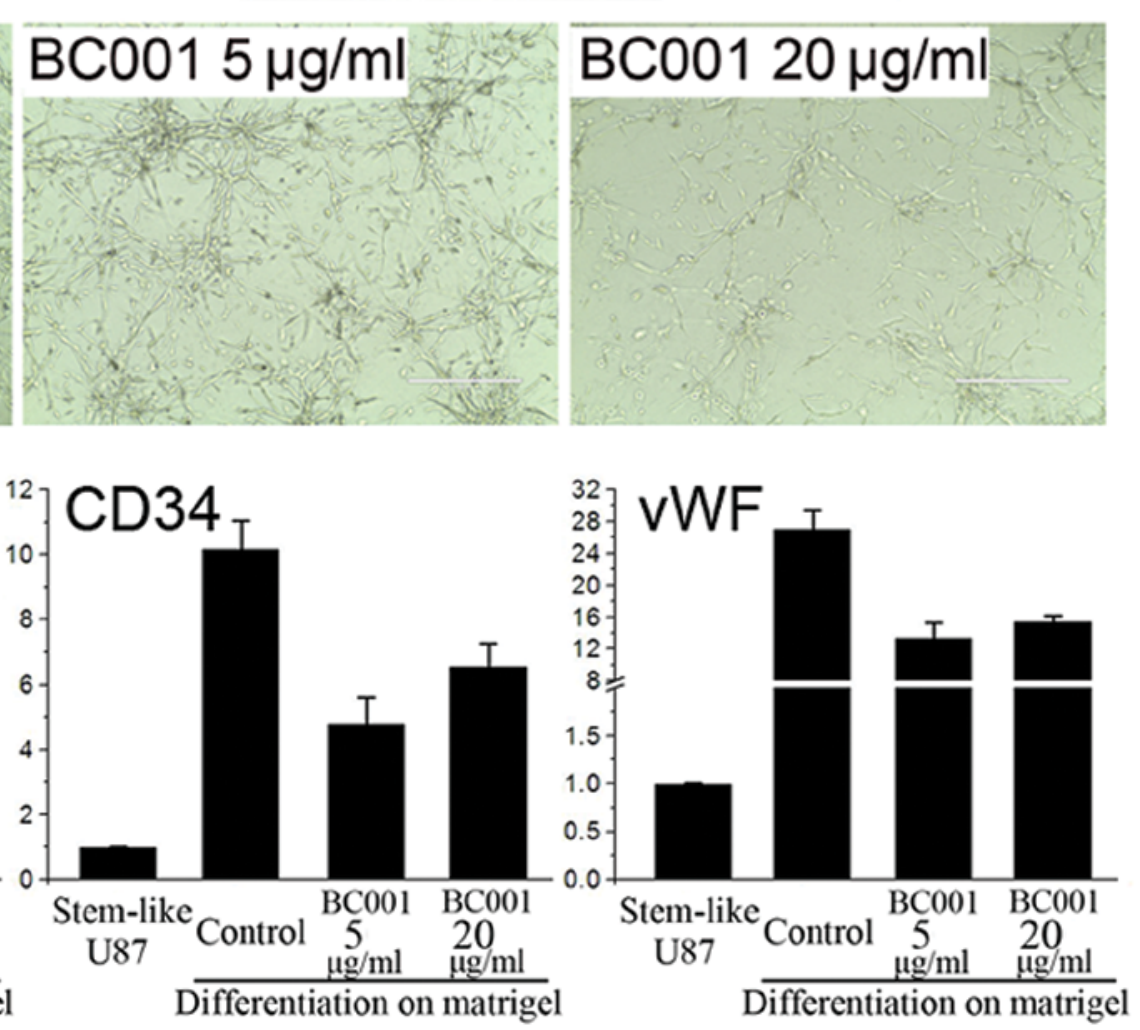

Figure 3. The effect of BC001 on transdifferentiation of stem-like U87. (A) Establishment of stem-like U87 spheres. Scale bar, 100 $\mu \mathrm{m}$. (B) CD133 ${ }^{+}$cells were identified by flow cytometry, the ratio of CD133+ cells was $31.82 \%$. (C) The expressions of CD133, Nestin and VEGFR2 in stem-like U87 cells were quantified using real-time PCR. (D) Stem-like U87 cells cultured under endothelial differentiation conditions developed morphological features of endothelial cells, and BC001 inhibited the transdifferentiation of stem-like U87 cells. Scale bar, $400 \mu \mathrm{m}$. (E) Stem-like U87 cells cultured under endothelial differentiation conditions developed phenotypical features of endothelial cells, the endothelial markers CD31, CD34, and vWF significantly increased, and BC001 reduced their expression.

this model (Fig. 3E). However, once the stem-like U87 cells were treated with BC001, capillary-like structure formation on Matrigel was impaired (Fig. 3D), accompanied by the decrease of CD31, CD34 and vWF mRNA expression (Fig. 3E). Taken together, BC001 effectively suppressed the transdifferentiation of stem-like U87 cells into ECs.
Anti-mouse VEGFR2 antibody (BC101) inhibits angiogenesis in vivo. We next determined whether the anti-VEGFR2 monoclonal antibody has direct antiangiogenic ability in vivo using Matrigel plug assay. Matrigel plugs containing VEGF and heparin were implanted subcutaneously into C57 mice, which triggered a robust angiogenic response 

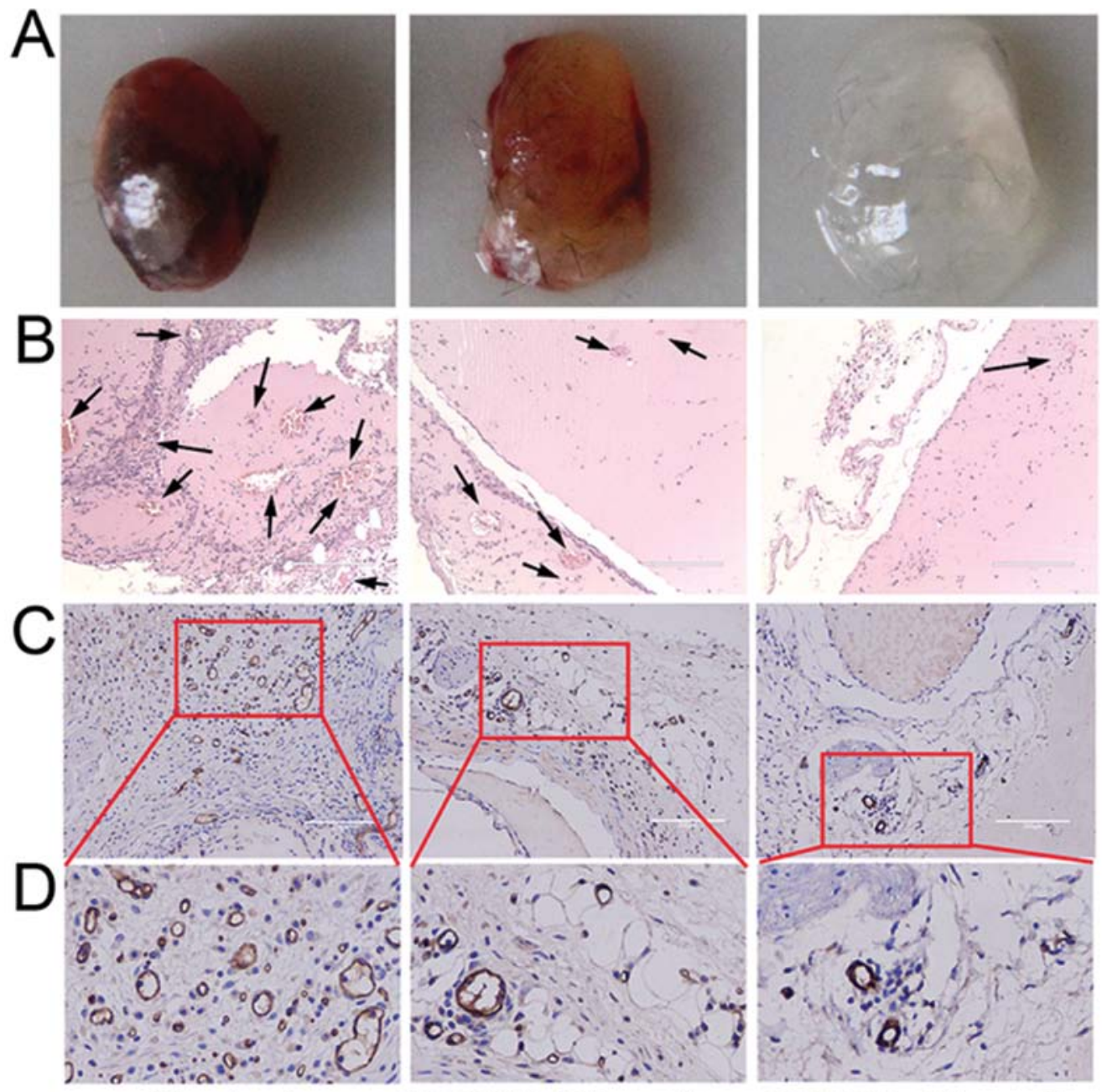

\section{Control BC101 $20 \mathrm{mg} / \mathrm{kg}$ BC101 $40 \mathrm{mg} / \mathrm{kg}$}

Figure 4. The anti-mouse VEGFR2 monoclonal antibody (BC101) inhibited angiogenesis in vivo. (A) BC101 significantly attenuated angiogenesis in vivo, using Matrigel plug assay. (B) Matrigel plugs treated with $\mathrm{BC} 101$, were fixed with formalin and 5- $\mu \mathrm{m}$ sections were stained with $\mathrm{H} \& \mathrm{E}$ staining. The arrows represented angiogenesis. Scale bar, $200 \mu \mathrm{m}$. (C) The number of vessels was counted in the presence or absence of BC101 at 20 and $40 \mathrm{mg} / \mathrm{kg}$, respectively. Scale bar, $200 \mu \mathrm{m}$. (D) Representative images of mCD31 positive cells from different groups.

after 10 days of implantation. BC101 treatment (20 and $40 \mathrm{mg} / \mathrm{kg}$ ) significantly inhibited VEGF-induced angiogenesis in a dose-dependent manner (Fig. 4A and B). Immunohistochemical analysis further revealed the reduced mouse CD31 expression in BC101-treated tumors (Fig. 4C and $\mathrm{D})$. These results indicated the potent antiangiogenic effect of $\mathrm{BC} 101$ in vivo.

Anti-mouse VEGFR2 antibody (BC101) inhibits B16F10 tumor growth. Next, mouse melanoma B16F10 homografts in $\mathrm{C} 57$ mice were used to evaluate the growth inhibitory property of $\mathrm{BC} 101$ in vivo. Compared with control group, $10 \mathrm{mg} / \mathrm{kg} \mathrm{BC} 101$ treatment resulted in a $26.31 \%$ decrease in tumor volume and a $26.91 \%$ reduction in tumor weight. The inhibitory effect of $20 \mathrm{mg} / \mathrm{kg} \mathrm{BC101}$ reached up to $\sim 60 \%$ $(\mathrm{P}<0.001)$. Of note, $40 \mathrm{mg} / \mathrm{kg} \mathrm{BC} 101$ treatment exhibited the best inhibitory effects, with a size reduction of $71.05 \%$ $(\mathrm{P}<0.001)$ and a weight reduction of $78.32 \%(\mathrm{P}<0.001)$. While bevacizumab caused $25 \%$ inhibition of tumor growth (Table II). These results provided evidence that $\mathrm{BC} 101$ strongly retarded B16F10 tumor growth in C57 mice (Fig. 5A and B), supporting the capacity of anti-VEGFR 2 to block angiogenesis and tumor growth in vivo.

BCOO1 ameliorates HCT116 tumor growth and angiogenesis. To investigate the antitumor effect of anti-human VEGFR2 BC001 on human xenograft tumors, we established human colorectal cancer cell HCT116 xenografts in nu/nu mice. Compared with control group, $10 \mathrm{mg} / \mathrm{kg}$ BC001 shows $40.58 \%$ inhibition $(\mathrm{P}<0.05)$ in tumor volume and $36.30 \%$ decrease $(\mathrm{P}<0.05)$ in tumor weight (Fig. $5 \mathrm{C}$ and $\mathrm{D})$. Five and $20 \mathrm{mg} / \mathrm{kg}$ BC001 can also cause $~ 30 \%$ inhibition. Bevacizumab $(4 \mathrm{mg} / \mathrm{kg})$, as positive control drug, resulted in a $64.51 \%(\mathrm{P}<0.001)$ shrinkage on tumor volume and a $62.09 \%(\mathrm{P}<0.001)$ decrease in tumor weight (Table II). H\&E staining further revealed the decreased microvessel density in tumors caused by treatment with BC001 $(10 \mathrm{mg} / \mathrm{kg})$ or bevacizumab ( $4 \mathrm{mg} / \mathrm{kg}$ ), which correlated with the decreased expression of VEGFR2 and hCD31 identified by immunohistochemistry staining (Fig. 6A-D). In addition, reduced Ki-67 expression and increased Caspase 3 expression caused by $\mathrm{BC} 001$ or bevacizumab treatment supported their effective 
Table II. The antitumor effects of BC101 or BC001.

\begin{tabular}{|c|c|c|c|c|c|c|c|}
\hline \multirow[b]{2}{*}{ Group } & \multicolumn{2}{|c|}{$\begin{array}{l}\text { Inhibition on } \\
\text { B16F10 tumors }\end{array}$} & \multirow[b]{2}{*}{ Group } & \multicolumn{2}{|c|}{$\begin{array}{c}\text { Inhibition on } \\
\text { HCT116 tumors }\end{array}$} & \multicolumn{2}{|c|}{$\begin{array}{c}\text { Inhibition on } \\
\text { BGC823 tumors }\end{array}$} \\
\hline & Volume & Weight & & Volume & Weight & Volume & Weight \\
\hline Bevacizumab (4 mg/kg) & $24.08 \%$ & $23.85 \%$ & Bevacizumab (4 mg/kg) & $64.51 \%$ & $62.09 \%$ & $71.46 \%$ & $75.10 \%$ \\
\hline BC101 (10 mg/kg) & $26.31 \%$ & $26.91 \%$ & $\mathrm{BC} 001(5 \mathrm{mg} / \mathrm{kg})$ & $29.47 \%$ & $25.59 \%$ & $42.35 \%$ & $40.87 \%$ \\
\hline BC101 (20 mg/kg) & $60.32 \%$ & $64.89 \%$ & BC001 (10 mg/kg) & $40.58 \%$ & $36.30 \%$ & $62.79 \%$ & $65.20 \%$ \\
\hline BC101 (40 mg/kg) & $71.05 \%$ & $78.32 \%$ & BC001 (20 mg/kg) & $32.02 \%$ & $29.21 \%$ & $48.17 \%$ & $49.33 \%$ \\
\hline
\end{tabular}
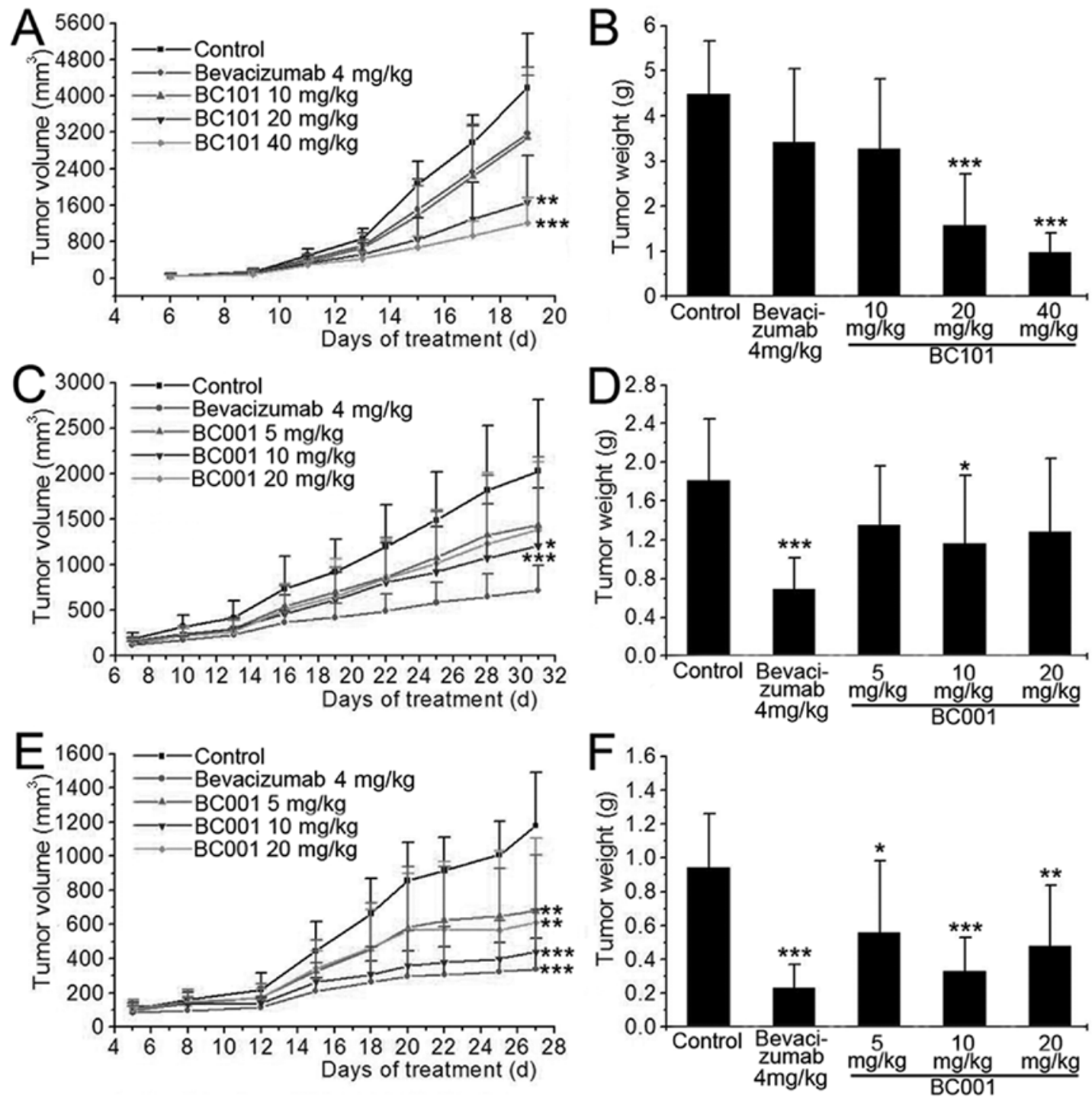

Figure 5. BC101 suppressed B16F10 tumor growth, and BC001 inhibited HCT116 and BGC823 tumor growth. (A) The growth of BC101 tumors was measured following treatment with control, bevacizumab or BC101. (B) Tumor weight was measured after 19-day treatment. (C) The tumor volume growth of HCT116 xenografts was measured following treatment with control, bevacizumab or BC001. (D) After 32-day treatment, the tumors of HCT116 xenografts were harvested, and tumor weight was measured. (E) Mice bearing BGC823 xenograft treated with control, bevacizumab or BC001 for 27 days, tumor volume was measured during treatment. (F) After treatment, the tumors of BGC823 xenografts were weighted. All results were expressed as the mean \pm SD.

roles in promotion of proliferation inhibition and apoptosis (Fig. 6E and F).

BC001 inhibits BGC823 tumor growth. To test the effects of BC001 on another human tumor type, we used a poorly differ- entiated human gastric carcinoma BGC823 xenograft model. Compared to control group, $10 \mathrm{mg} / \mathrm{kg}$ BC001 showed obvious inhibitory effect on BGC823 tumor growth (Fig. 5E and F), with $62.79 \%$ reduction in tumor weight $(\mathrm{P}<0.001)$ and $65.20 \%$ reduction in tumor volume $(\mathrm{P}<0.001)$. BC001 5 and $20 \mathrm{mg} / \mathrm{kg}$ 

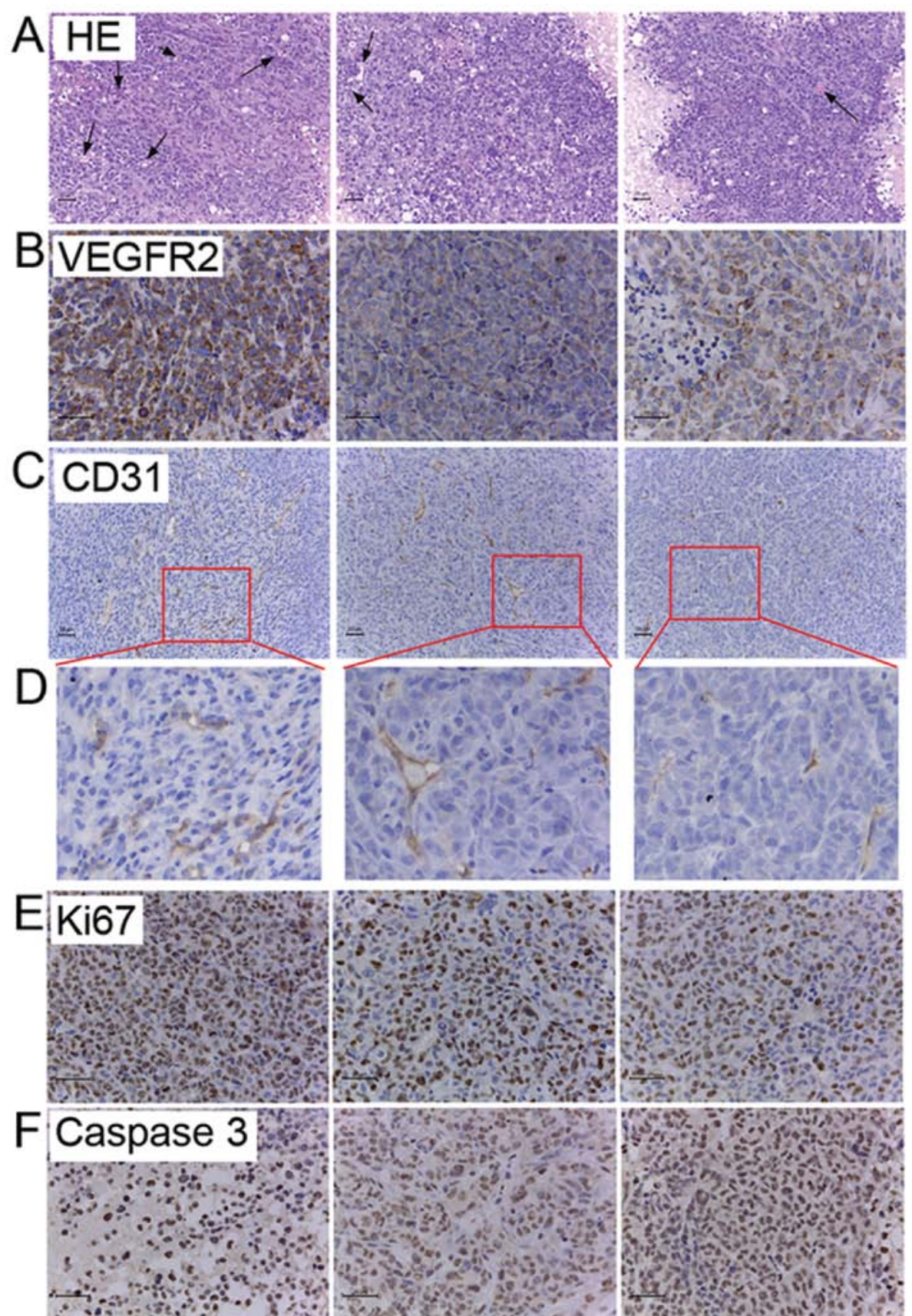

Control
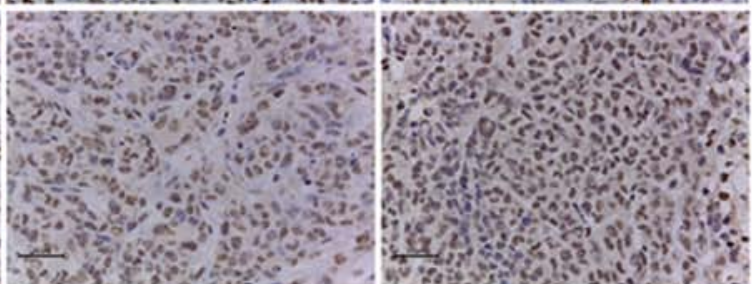

$\mathrm{BC001}$

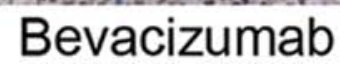

Figure 6. Histology and immunohistochemistry of HCT116 xenografts. (A) H\&E staining of HCT116 xenografts in either BC001 or bevacizumab-treated mice. The arrows indicate angiogenesis. Scale bar, $20 \mu \mathrm{m}$. (B) Quantification of VEGFR2 expression from HCT116 xenografts treated with control, BC001 or bevacizumab. Scale bar, $20 \mu \mathrm{m}$. (C) Quantification of hCD31 expression from HCT116 xenografts treated with control, BC001 or bevacizumab. Scale bar, $20 \mu \mathrm{m}$. (D) Representative images of hCD31 positive cells from different groups. (E) To quantify proliferation, and the positive nucleus of Ki-67 immunostaining was calculated. Scale bar, $20 \mu \mathrm{m}$. (F) Results about Caspase 3 immunostaining showed apoptotic cells in HCT116 xenografts. Scale bar, $20 \mu \mathrm{m}$.

treatments also effectively delayed tumor growth, showing 40-50\% inhibitory effects (Table II). Positive control drug bevacizumab ( $4 \mathrm{mg} / \mathrm{kg}$ ) exhibited $>70 \%$ inhibitory effect on tumor growth. These data confirmed the obvious antitumor effects of anti-human VEGFR2 BC001 on human xenograft tumors.

\section{Discussion}

To date, malignant tumors are a leading cause of mortality in the developed world, but a large proportion of patients do not have successful therapeutic strategies (30). Furthermore, there is no doubt that tumor angiogenesis is essential for the process of tumor growth, invasion and metastatic dissemination, more importantly, VEGF ligands and their receptors play a central role in these processes $(31,32)$. For example, as an essential tyrosine kinase receptor for VEGF-mediated physiological responses, VEGFR2 is not only found in endothelial cells, but may also be upregulated on the surface of some tumor cells $(33,34)$. Recent studies suggest that VEGF-VEGFR2 interplay is a novel and attractive target in therapy of malignant 
tumors (35), therefore, BC001 was developed. However, little information is available on the functions of the potential drug in tumor angiogenesis and tumor growth. In our experiment, we demonstrate that BC001 comprehensively inhibits VEGFstimulated endothelial cells migration in vitro. Moreover, tube-formation assay is one of the well-established in vitro angiogenesis assays (36). BC001 blocked the tube-formation of HUVECs, when cultured on Matrigel. In addition, BC001 effectively inhibited the transdifferentiation of glioma stem cells into endothelial cells.

In theory, anti-human VEGFR2 antibody BC001 has no activity against the mouse VEGFR2, so a rat anti-mouse antibody, BC101 was developed to perform VEGFR2 inhibition studies based on the mouse model. BC101 exhibited high affinity for Flk1 (the murine version of VEGFR2), and our research confirmed BC101 significantly inhibited VEGFinduced angiogenesis by Matrigel plug assay, and showed BC101 significantly suppresseed the growth of mouse B16F10 homograft tumors. Together, anti-VEGFR2 antibody inhibited angiogenesis and tumor growth.

We observed that BC001 significantly inhibited the growth of human colorectal tumor HCT116 and human gastric tumor BGC823 xenografts. H\&E and immunohistochemical staining of BC001-treated HCT116 tumors further showed decreased microvessel density. We observed that the inhibitory effect of BC001 on BGC823 tumor growth is better than that on HCT116 growth, which suggested BC001 might show great therapeutic potential to gastric tumor, compared to colorectal tumor. In addition, we recorded that the inhibitory effect of $10 \mathrm{mg} / \mathrm{kg} \mathrm{BC001} \mathrm{treatment} \mathrm{was} \mathrm{as} \mathrm{good} \mathrm{as,} \mathrm{or} \mathrm{even}$ better, than that of BC001 $20 \mathrm{mg} / \mathrm{kg}$ treatment. The doseindependent problem also existed in clinical research. The antitumor effects of some antiangiogenic drugs are often not dose-dependent, and there is a U-shaped curve between the dosage of drugs and therapeutic effect (37). It is unclear why the phenomenon occurs, and further studies should be done to illuminate the real reasons, which may help to establish the optimal dose.

In addition, our research showed that the antitumor effects of anti-human VEGFR2 antibody BC001 on HCT116 and BGC823 are lower than anti-human VEGF antibody bevacizumab. Due to high homology of VEGF gene and poor homology of VEGFR2 gene between human and mouse, BC001 exhibited no activity against the mouse VEGFR2 receptor, while bevacizumab can block the human and mouse VEGF pathways. Furthermore, angiogenesis of human tumor xenografts in nude mice not only depends on human tumor cells or tumor stem cells, but also requires regulation of immune cells, bone marrow-derived progenitor cells, and support from the host (38). For example, macrophages and fibroblasts, produce a wide variety of proangiogenic factors, participating in the formation of tumor blood vessels $(39,40)$. Therefore, it was not surprising to observe that bevacizumab showed better inhibitory effect than BC001 on human tumor xenograft mouse model. Nevertheless, BC001 should exhibit more obvious antitumor effects, when it is used in clinical treatment.

In conclusion, our results demonstrate BC001 apparently inhibits angiogenesis and suppresses tumor growth in vivo. and in vitro. However, various combinations of strategies, including radiotherapy or chemotherapy, should be demon- strated to achieve synergistic effects on inhibiting tumors, and it also remains to be investigated whether BC001 is suitable for other tumor types.

\section{Acknowledgements}

This study was supported by the National Key Technologies R\&DProgramforNew Drugs (grantno.2012ZX09301003-001).

\section{References}

1. Folkman J: Angiogenesis: an organizing principle for drug discovery? Nat Rev Drug Discov 6: 273-286, 2007.

2. Chung AS, Lee J and Ferrara N: Targeting the tumour vasculature: insights from physiological angiogenesis. Nat Rev Cancer 10: 505-514, 2010.

3. Ebos JM and Kerbel RS: Antiangiogenic therapy: impact on invasion, disease progression, and metastasis. Nat Rev Clin Oncol 8: 210-221, 2011.

4. Wong ML, Prawira A, Kaye AH and Hovens CM: Tumour angiogenesis: its mechanism and therapeutic implications in malignant gliomas. J Clin Neurosci 16: 1119-1130, 2009.

5. Brower V: Tumor angiogenesis - new drugs on the block. Nat Biotechnol 17: 963-968, 1999.

6. Olsson AK, Dimberg A, Kreuger J and Claesson-Welsh L: VEGF receptor signalling - in control of vascular function. Nat Rev Mol Cell Biol 7: 359-371, 2006.

7. Teicher BA: Antiangiogenic agents and targets: a perspective. Biochem Pharmacol 81: 6-12, 2011.

8. Conley SJ, Gheordunescu E, Kakarala P, Newman B, Korkaya H, Heath AN, et al: Antiangiogenic agents increase breast cancer stem cells via the generation of tumor hypoxia. Proc Natl Acad Sci USA 109: 2784-2789, 2012.

9. Xu HY, Pan YM, Chen ZW, Lin Y, Wang LH, Chen YH, et al: 12-Deoxyphorbol 13-palmitate inhibit VEGF-induced angiogenesis via suppression of VEGFR-2-signaling pathway. J Ethnopharmacol 146: 724-733, 2013.

10. Liao X, Zhou X, Mak NK and Leung KN: Tryptanthrin inhibits angiogenesis by targeting the VEGFR2-mediated ERK1/2 signalling pathway. PLoS One 8: e82294, 2013.

11. Holzer TR, Fulford AD, Nedderman DM, Umberger TS, Hozak RR, Joshi A, et al: Tumor cell expression of vascular endothelial growth factor receptor 2 is an adverse prognostic factor in patients with squamous cell carcinoma of the lung. PLoS One 8: e80292, 2013.

12. Lynn KD, Udugamasooriya DG, Roland CL, Castrillon DH, Kodadek TJ and Brekken RA: GU81, a VEGFR2 antagonist peptoid, enhances the anti-tumor activity of doxorubicin in the murine MMTV-PyMT transgenic model of breast cancer. BMC Cancer 10: 397, 2010.

13. Soda Y, Marumoto T, Friedmann-Morvinski D, Soda M, Liu F, Michiue $\mathrm{H}$, et al: Transdifferentiation of glioblastoma cells into vascular endothelial cells. Proc Natl Acad Sci USA 108: 4274-4280, 2011.

14. Hutchinson E: Stem cells: tumour stem cells generate vasculature. Nat Rev Cancer 11: 4, 2011.

15. Ricci-Vitiani L, Pallini R, Biffoni M, Todaro M, Invernici G, Cenci $\mathrm{T}$, et al: Tumour vascularization via endothelial differentiation of glioblastoma stem-like cells. Nature 468: 824-828, 2010.

16. Hamerlik P, Lathia JD, Rasmussen R, Wu Q, Bartkova J, Lee M, et al: Autocrine VEGF-VEGFR2-Neuropilin-1 signaling promotes glioma stem-like cell viability and tumor growth. J Exp Med 209: 507-520, 2012.

17. Calabrese C, Poppleton H, Kocak M, Hogg TL, Fuller C, Hamner B, et al: A perivascular niche for brain tumor stem cells. Cancer Cell 11: 69-82, 2007.

18. Saraswati S and Agrawal SS: Brucine, an indole alkaloid from Strychnos nux-vomica attenuates VEGF-induced angiogenesis via inhibiting VEGFR2 signaling pathway in vitro and in vivo. Cancer Lett 332: 83-93, 2013.

19. Zhang G, Panigrahy D, Mahakian LM, Yang J, Liu JY, Stephen Lee KS, et al: Epoxy metabolites of docosahexaenoic acid (DHA) inhibit angiogenesis, tumor growth, and metastasis. Proc Natl Acad Sci USA 110: 6530-6535, 2013.

20. Wang R, Chadalavada K, Wilshire J, Kowalik U, Hovinga KE, Geber A, et al: Glioblastoma stem-like cells give rise to tumour endothelium. Nature 468: 829-833, 2010. 
21. Pang X, Yi T, Yi Z, Cho SG, Qu W, Pinkaew D, et al: Morelloflavone, a biflavonoid, inhibits tumor angiogenesis by targeting rho GTPases and extracellular signal-regulated kinase signaling pathways. Cancer Res 69: 518-525, 2009.

22. Adini A, Fainaru O, Udagawa T, Connor KM, Folkman J and D'Amato RJ: Matrigel cytometry: a novel method for quantifying angiogenesis in vivo. J Immunol Methods 342: 78-81, 2009.

23. Gao Z, Zheng J, Yang B, Wang Z, Fan H, Lv Y, et al: Sonodynamic therapy inhibits angiogenesis and tumor growth in a xenograft mouse model. Cancer Lett 335: 93-99, 2013.

24. Evellin S, Galvagni F, Zippo A, Neri F, Orlandini M, Incarnato D, et al: FOSL1 controls the assembly of endothelial cells into capillary tubes by direct repression of $\alpha \mathrm{v}$ and $\beta 3$ integrin transcription. Mol Cell Biol 33: 1198-1209, 2013.

25. Scully S, Francescone R, Faibish M, Bentley B, Taylor SL Oh D, et al: Transdifferentiation of glioblastoma stem-like cells into mural cells drives vasculogenic mimicry in glioblastomas. J Neurosci 32: 12950-12960, 2012.

26. Cheng L, Huang Z, Zhou W, Wu Q, Donnola S, Liu JK, et al: Glioblastoma stem cells generate vascular pericytes to support vessel function and tumor growth. Cell 153: 139-152, 2013.

27. Dong J, Zhao Y, Huang Q, Fei X, Diao Y, Shen Y, et al: Glioma stem/progenitor cells contribute to neovascularization via transdifferentiation. Stem Cell Rev 7: 141-152, 2011

28. Ribatti D: Cancer stem cells and tumor angiogenesis. Cancer Lett 321: 13-17, 2012

29. Bao S, Wu Q, Sathornsumetee S, Hao Y, Li Z, Hjelmeland AB, et al: Stem cell-like glioma cells promote tumor angiogenesis through vascular endothelial growth factor. Cancer Res 66 : 7843-7848, 2006.

30. Chanthery YH, Gustafson WC, Itsara M, Persson A, Hackett CS, Grimmer M, et al: Paracrine signaling through MYCN enhances tumor-vascular interactions in neuroblastoma. Sci Transl Med 4 $115 \mathrm{ra3}, 2012$
31. Carmeliet P and Jain RK: Molecular mechanisms and clinical applications of angiogenesis. Nature 473: 298-307, 2011.

32. Potente M, Gerhardt $\mathrm{H}$ and Carmeliet P: Basic and therapeutic aspects of angiogenesis. Cell 146: 873-887, 2011.

33. Ellis LM and Hicklin DJ: VEGF-targeted therapy: mechanisms of anti-tumour activity. Nat Rev Cancer 8: 579-591, 2008

34. Goel HL and Mercurio AM: VEGF targets the tumour cell. Nat Rev Cancer 13: 871-882, 2013.

35. Chatterjee S, Heukamp LC, Siobal M, Schttle J, Wieczorek C, Peifer M, et al: Tumor VEGF: VEGFR2 autocrine feed-forward loop triggers angiogenesis in lung cancer. J Clin Invest 123: 1732-1740, 2013.

36. Gao D, Nolan DJ, Mellick AS, Bambino K, McDonnell K and Mittal V: Endothelial progenitor cells control the angiogenic switch in mouse lung metastasis. Science 319: 195-198, 2008.

37. Huang YH, Yuan JP, Righi E, Kamoun WS, Ancukiewicz M, Nezivar J, et al: Vascular normalizing doses of antiangiogenic treatment reprogram the immunosuppressive tumor microenvironment and enhance immunotherapy. Proc Natl Acad Sci USA 109: 17561-17566, 2012.

38. Spring H, Schuler T, Arnold B, Hammerling GJ and Ganss R: Chemokines direct endothelial progenitors into tumor neovessels. Proc Natl Acad Sci USA 102: 18111-18116, 2005.

39. Narunsky L, Oren R, Bochner F and Neeman M: Imaging aspects of the tumor stroma with therapeutic implications. Pharmacol Ther 141: 192-208, 2014.

40. Tang X: Tumor-associated macrophages as potential diagnostic and prognostic biomarkers in breast cancer. Cancer Lett 332: 3-10, 2013. 